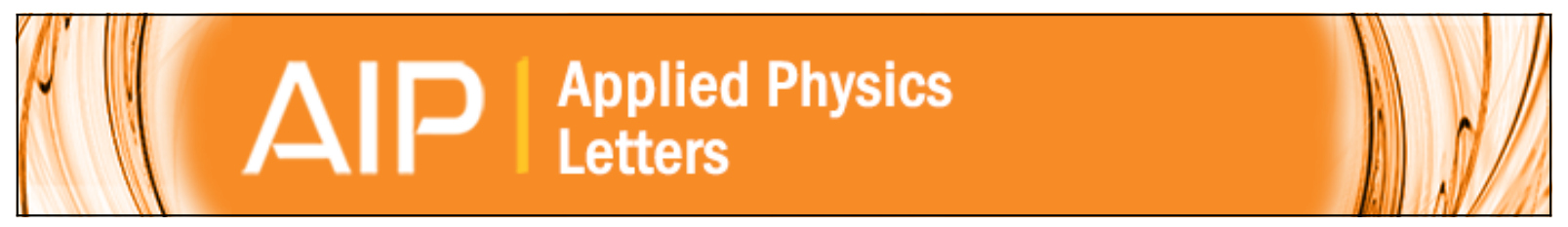

\title{
Hydrogen and deuterium incorporation and transport in hafnium-based dielectric films
} on silicon

R. P. Pezzi, L. Miotti, K. P. Bastos, G. V. Soares, C. Driemeier, I. J. R. Baumvol, P. Punchaipetch, G. Pant, B. E. Gnade, R. M. Wallace, A. Rotondaro, J. M. Visokay, J. J. Chambers, and L. Colombo

Citation: Applied Physics Letters 85, 3540 (2004); doi: 10.1063/1.1801682

View online: http://dx.doi.org/10.1063/1.1801682

View Table of Contents: http://scitation.aip.org/content/aip/journal/apl/85/16?ver=pdfcov

Published by the AIP Publishing

\section{Articles you may be interested in}

Environment of hafnium and silicon in Hf-based dielectric films: An atomistic study by $\mathrm{x}$-ray absorption spectroscopy and $x$-ray diffraction

Appl. Phys. Lett. 86, 212906 (2005); 10.1063/1.1935042

High-temperature phase stability of hafnium aluminate films for alternative gate dielectrics

J. Appl. Phys. 95, 3772 (2004); 10.1063/1.1652240

Thermal behavior of hafnium-based ultrathin films on silicon

J. Vac. Sci. Technol. A 21, 1424 (2003); 10.1116/1.1575218

Hafnium interdiffusion studies from hafnium silicate into silicon

Appl. Phys. Lett. 79, 4192 (2001); 10.1063/1.1425466

Electrical properties of hafnium silicate gate dielectrics deposited directly on silicon

Appl. Phys. Lett. 74, 2854 (1999); 10.1063/1.124036

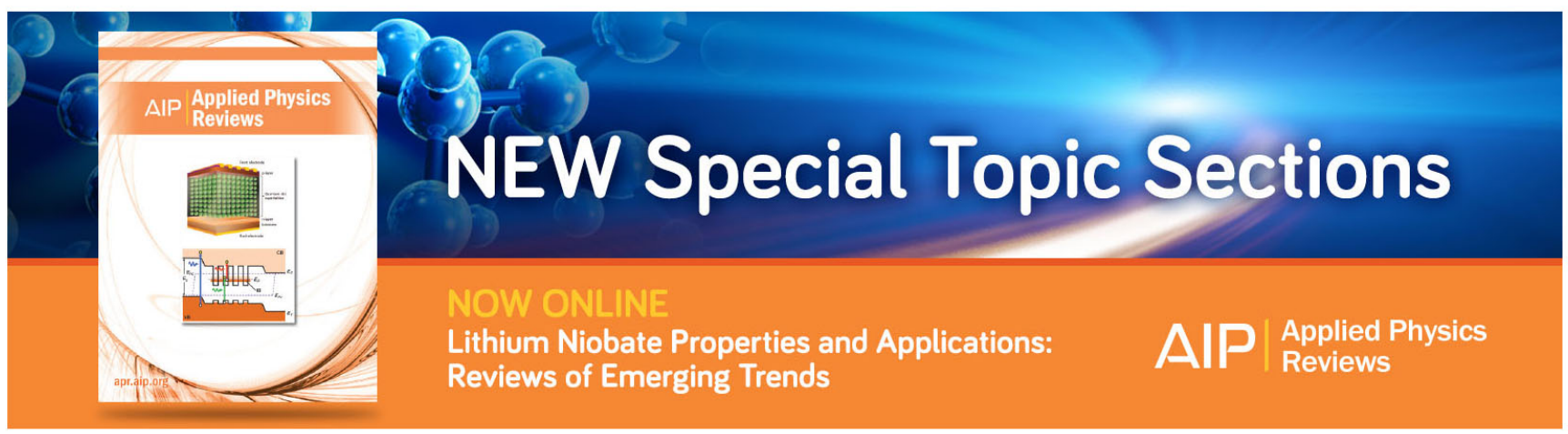




\title{
Hydrogen and deuterium incorporation and transport in hafnium-based dielectric films on silicon
}

\author{
R. P. Pezzi, ${ }^{\text {a) }}$ L. Miotti, K. P. Bastos, G. V. Soares, and C. Driemeier \\ Instituto de Física, UFRGS, Av. Bento Gonçalves, 9500, Porto Alegre, RS, Brazil 91509-900 \\ I. J. R. Baumvol \\ Centro de Ciências Exatas e Tecnológicas, UCS, Caxias do Sul, RS, Brazil 95070-560 \\ P. Punchaipetch, G. Pant, B. E. Gnade, and R. M. Wallace \\ Department of Electrical Engineering, University of Texas at Dallas, Richardson, Texas 75083
}

A. Rotondaro, J. M. Visokay, J. J. Chambers, and L. Colombo

Silicon Technology Development, Texas Instruments Incorporated, Dallas, Texas

(Received 24 March 2004; accepted 11 August 2004)

\begin{abstract}
Hydrogen and deuterium incorporation into nitrided and non-nitrided hafnium silicate films on $\mathrm{Si}$ during thermal annealing in ${ }^{1} \mathrm{H}$ - and ${ }^{2} \mathrm{H}$-containing atmospheres was investigated. ${ }^{1} \mathrm{H}$ profiling was accessed by means of nuclear resonant reaction profiling, whereas ${ }^{2} \mathrm{H}$ incorporation was quantified by nuclear reaction analysis. The effects of preannealing in different atmospheres and temperatures were determined, as well as the losses of ${ }^{1} \mathrm{H}$ and ${ }^{2} \mathrm{H}$ from these structures during postannealing in vacuum. The results reveal a rather uniform depth distribution of incorporated ${ }^{1} \mathrm{H}$, in striking contrast with previous studies on hydrogen in silicon oxide and oxynitrides and hafnium oxide films on $\mathrm{Si}$. These results are discussed in terms of the defects present in each one of the structures studied here. (C) 2004 American Institute of Physics. [DOI: 10.1063/1.1801682]
\end{abstract}

Intensive efforts have been made in recent years in order to retain $\mathrm{SiO}_{2}$ or $\mathrm{SiO}_{x} \mathrm{~N}_{y}$ as the gate dielectric material in metal-oxide-semiconductor field-effect transistor (MOSFET) devices. However, the replacement of these materials with an alternative one holding a higher dielectric constant (high- $k$ dielectrics) in advanced, ultralarge scale integration devices has enticed attention, owing to the exponential increase of the gate leakage current with decreasing gate dielectric film thickness. ${ }^{1-9}$ Hydrogen incorporation mechanisms underlying the forming-gas sintering step responsible for passivation of the electrical activity near the dielectric/ semiconductor interface has been little studied so far in high- $k$ dielectrics. ${ }^{10,11}$ Furthermore, deuterium $\left({ }^{2} \mathrm{H}\right)$ passivation of the $\mathrm{SiO}_{2} / \mathrm{Si}$ or $\mathrm{SiO}_{x} \mathrm{~N}_{y} / \mathrm{Si}$ interfaces was introduced ${ }^{12}$ as a superior alternative to increase the stability of the $\mathrm{H}$-electrically passivated dielectric / $\mathrm{Si}$ interface and thus reliability, deserving detailed study in high- $k$ dielectrics. ${ }^{13-18}$

In this letter we present hydrogen and deuterium areal densities and concentration profiles in $\mathrm{HfSiO}, \mathrm{HfSiON}$, and HfSiN films on $\mathrm{Si}(001)$. The thermal stability of ${ }^{1} \mathrm{H}$ and ${ }^{2} \mathrm{H}$ as well as the effects of annealing previously to hydrogen or deuterium loading were also accessed by submitting the structures to annealing routines that simulate different steps of device manufacturing. We particularly examine the effect on the ${ }^{1} \mathrm{H}$ - and ${ }^{2} \mathrm{H}$-incorporation dynamics of typical rapid thermal annealing at $1000^{\circ} \mathrm{C}$ responsible for source and drain dopant activation, which also yields a densification of hafnium silicate gate dielectric films. ${ }^{19}$

The investigated thin films were all sputtered from a HfSi target in the following routes:

reactive sputtering deposition of thick $(50 \mathrm{~nm})$, oxygen (nitrogen) defficient double oxide (nitride) films, ${ }^{1}$ namely $\left(\mathrm{HfO}_{2}\right)_{x}\left(\mathrm{SiO}_{2}\right)_{1-x}$ and $(\mathrm{HfN})_{x}\left(\mathrm{Si}_{2} \mathrm{~N}_{3}\right)_{1-x}$ with atomic ratio $\mathrm{Si} / \mathrm{Hf}=1.3$, hereafter called react-HfSiO and react-HfSiN.

(ii) thin $\mathrm{HfSiO}$ and $\mathrm{HfSiON}$ films (4 and $2 \mathrm{~nm}$ thick, respectively) produced by ultraviolet ozone oxidation ${ }^{20}$ of $\mathrm{HfSi}$ and $\mathrm{HfSiN}$ films on $\mathrm{Si}(\mathrm{Si} / \mathrm{Hf}=1.7$ ratio), with average stoichiometries $\left(\mathrm{HfO}_{2}\right)_{x}\left(\mathrm{SiO}_{2}\right)_{1-x}$ and $(\mathrm{HfNO})_{x}(\mathrm{SiNO})_{1-x}$, this last with $\mathrm{O} / \mathrm{N}=3.5$ atomic ratio, hereafter called UVOZ-HfSiO and UVOZHfSiON.

Hydrogen concentrations versus depth were determined by nuclear resonant reaction profiling (NRP) using the ${ }^{1} \mathrm{H}\left({ }^{15} \mathrm{~N}, \alpha \gamma\right){ }^{12} \mathrm{C}$ nuclear reaction near the resonance at $6.385 \mathrm{MeV},{ }^{14}$ while deuterium areal densities were determined by NRA using the ${ }^{2} \mathrm{H}\left({ }^{3} \mathrm{He}, p\right){ }^{4} \mathrm{He}$ nuclear reaction ${ }^{13}$ at $700 \mathrm{keV}$. Samples were annealed in a Joule-effect heated furnace or by rapid thermal annealing, in vacuum ( $p$ $\sim 10^{-7}$ mbar, vacuum annealing), in 50 mbar of $\mathrm{N}_{2}\left(\mathrm{~N}_{2}\right.$ annealing), or in 50 mbar of $\mathrm{O}_{2}\left(\mathrm{O}_{2}\right.$ annealing). ${ }^{1} \mathrm{H}$ and ${ }^{2} \mathrm{H}$ loadings were carried, respectively, in 500 mbar of forminggas $\left(90 \% \mathrm{~N}_{2}: 10 \% \mathrm{H}_{2}\right)$ (FG annealing) or $50 \mathrm{mbar}$ of ${ }^{2} \mathrm{H}\left({ }^{2} \mathrm{H}\right.$ annealing) for $30 \mathrm{~min}$ at $500^{\circ} \mathrm{C}$.

Figure 1 shows the excitation curves of the ${ }^{1} \mathrm{H}\left({ }^{15} \mathrm{~N}, \alpha \gamma\right){ }^{12} \mathrm{C}$ nuclear reaction near the resonance at $6.385 \mathrm{MeV}$ for the 50-nm-thick react-HfSiO (top) and reactHfSiN (bottom) structures. Since the NRP analyses were performed ex situ, there is a strong peak at the energy corresponding to the sample surface, see Fig. 1(inset), owing to $\mathrm{H}$ incorporation in this region as a consequence of exposure to air. Furthermore, the $\mathrm{H}$ concentration levels in the bulk of the as-deposited films (solid lines) are very low, as expected for sputter-deposited films in the present conditions. After FG annealing (open circles) hydrogen is found uniformly distributed from the surface down to the interface in both $\mathrm{HfSiO}$ and $\mathrm{HfSiN}$ films on $\mathrm{Si}$, in contrast with previous results for $\mathrm{SiO}_{2}$ as well as for $\mathrm{HfO}_{2}$ films, where a peak is observed in 


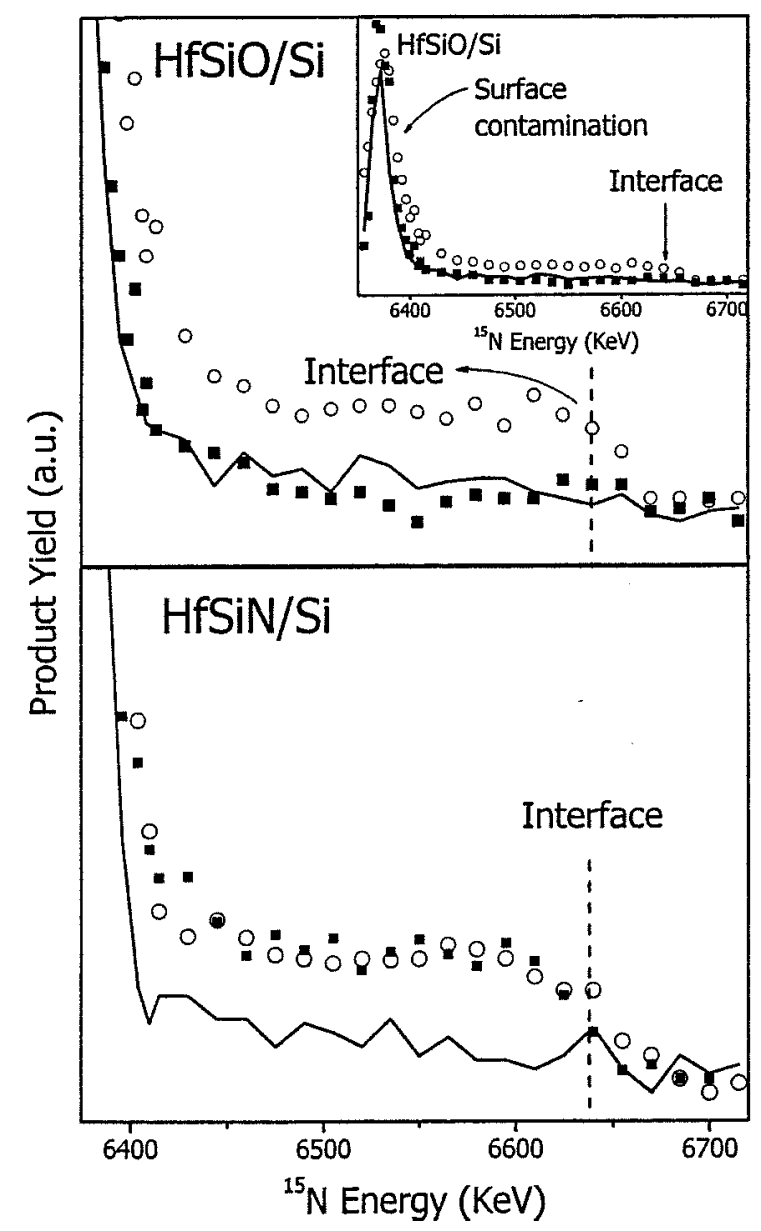

FIG. 1. Excitation curves of the ${ }^{1} \mathrm{H}\left({ }^{15} \mathrm{~N}, \alpha \gamma\right){ }^{12} \mathrm{C}$ nuclear reaction around the resonance at $6.385 \mathrm{MeV}$ from the 50-nm-thick react-HfSiO/Si (top) and react-HfSiN/Si (bottom) structures: as-prepared samples (solid lines); annealed in 500 mbar of forming-gas- $90 \% \mathrm{~N}_{2}, 10 \% \mathrm{H}_{2}$-for $30 \mathrm{~min}$ at $500^{\circ} \mathrm{C}$ (open circles); and annealing in forming-gas followed by vacuumannealing for $30 \mathrm{~min}$ at $500^{\circ} \mathrm{C}$ (closed squares). The inset shows the complete excitation curves, including the contributions from the surface contamination layer.

near-interface regions. Thus, the H-trapping sites, either dangling bonds, stoichiometry faults, or other chemically active defects are rather uniformly distributed in the react-HfSiO and react-HfSiN films, whereas they are strongly concentrated in the near-interface regions in $\mathrm{SiO}_{2}$ or $\mathrm{HfO}_{2}$ films on $\mathrm{Si}^{21,22}$

The incorporation and stability of ${ }^{2} \mathrm{H}$ in the same react$\mathrm{HfSiO}$ and react-HfSiN films on $\mathrm{Si}$ were accessed by annealing in ${ }^{2} \mathrm{H}_{2}$ instead of forming gas. The ${ }^{2} \mathrm{H}$ areal densities as determined by the ${ }^{2} \mathrm{H}\left({ }^{3} \mathrm{He}, p\right){ }^{4} \mathrm{He}$ nuclear reaction are shown in Fig. 2. Besides corroborating the effects observed in Fig. 1, Fig. 2 reveals that ${ }^{2} \mathrm{H}$ incorporates in substantially higher amounts into react-HfSiN than into the react-HfSiO.

Figure 3 shows the excitation curves of the ${ }^{1} \mathrm{H}\left({ }^{15} \mathrm{~N}, \alpha \gamma\right){ }^{12} \mathrm{C}$ nuclear reaction from react- $\mathrm{HfSiO} / \mathrm{Si}$ and react-HfSiN/Si structures first annealed in $\mathrm{N}_{2}$ at $500^{\circ} \mathrm{C}$ and then $\mathrm{H}$ loaded (triangles). One notices a reduction in the level of $\mathrm{H}$ incorporation into both react-HfSiO and reactHfSiN with respect to the non-preanneled samples. Thus, a fraction of H-trapping defects in both structures are removed during $\mathrm{N}_{2}$ annealing, while keeping their corresponding depth distributions unchanged.

The much thinner UVOZ-HfSiO $(4 \mathrm{~nm})$ and UVOZ$\mathrm{HfSiON}(2 \mathrm{~nm})$ films on $\mathrm{Si}$, were also annealed in ${ }^{2} \mathrm{H}_{2}$ atmo-

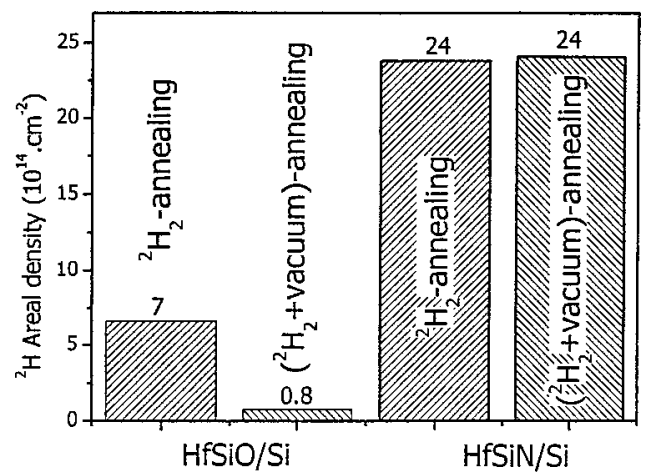

FIG. 2. Deuterium areal densities incorporated into the 50-nm-thick react$\mathrm{HfSiO} / \mathrm{Si}$ and react-HfSiN/Si structures after the indicated annealing sequences, as determined by nuclear reaction analysis using the ${ }^{2} \mathrm{H}\left({ }^{3} \mathrm{He}, p\right)^{4} \mathrm{He}$ nuclear reaction at $700 \mathrm{keV} . \mathrm{D}_{2}$-loading at $450^{\circ} \mathrm{C}$ for $30 \mathrm{~min}$; vacuumannealing at $500^{\circ} \mathrm{C}$ for $30 \mathrm{~min}$. The errors in the ${ }^{2} \mathrm{H}$ areal densities are $10 \%$.

sphere. Table I shows the ${ }^{2} \mathrm{H}$ areal densities as determined by NRA using the ${ }^{2} \mathrm{H}\left({ }^{3} \mathrm{He}, p\right){ }^{4} \mathrm{He}$ nuclear reaction, obtained after submitting the films to different annealing routes prior to ${ }^{2} \mathrm{H}$ loading. Preannealing in $\mathrm{N}_{2}$ or in $\mathrm{O}_{2}$ reduced the ${ }^{2} \mathrm{H}$ incorporation in UVOZ-HfSiO whereas in UVOZ-HfSiON, ${ }^{2} \mathrm{H}$ incorporation is only reduced by $\mathrm{O}_{2}$ preannealing. Table I reveals that there is a one order of magnitude larger reduction in the amount of incorporated ${ }^{2} \mathrm{H}$ in both UVOZ - $\mathrm{HfSiO}$ and UVOZ-HfSiON structures when submitted to rapid thermal preannealing at $1000^{\circ} \mathrm{C}$ in $\mathrm{N}_{2}$ or $\mathrm{N}_{2}$ followed by $\mathrm{O}_{2}$, as compared to those preannealed at $400-500^{\circ} \mathrm{C}$. These data indicate a strong reduction in defect density in these dielectric films, which may be correlated to the previously observed ${ }^{19}$ densification of hafnium silicate films on $\mathrm{Si}$ at high temperatures. The $\mathrm{N}$ content, as measured by NRA

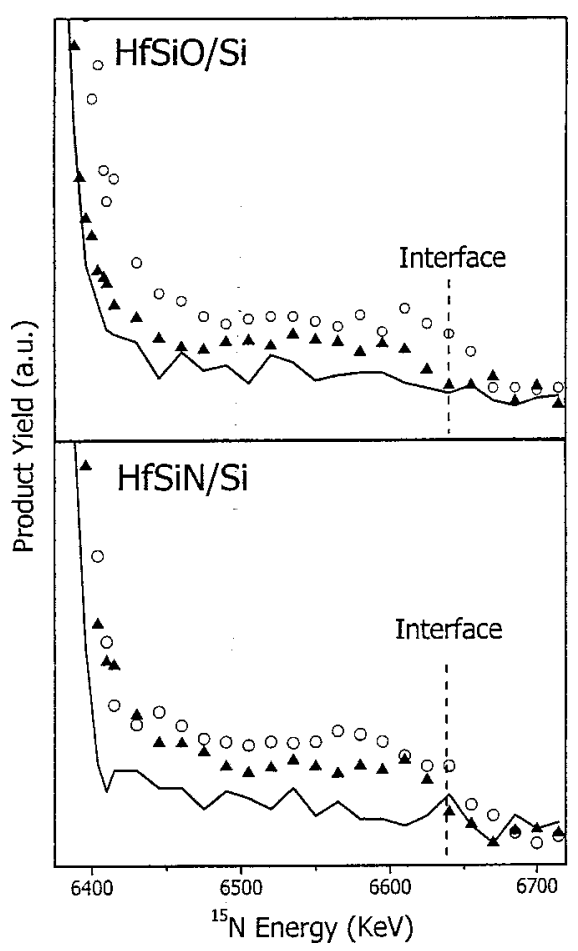

FIG. 3. Excitation curves of the ${ }^{1} \mathrm{H}\left({ }^{15} \mathrm{~N}, \alpha \gamma\right){ }^{12} \mathrm{C}$ nuclear reaction around the resonance at $6.385 \mathrm{MeV}$ from the 50-nm-thick react-HfSiO/Si and react$\mathrm{HfSiN} / \mathrm{Si}$ structures. The solid lines stand for the as-prepared samples, open circles for the forming-gas annealed samples, and triangles for the $\mathrm{N}_{2}$ preannealed samples followed by forming-gas annealing. 
TABLE I. ${ }^{2} \mathrm{H}$ areal densities, as determined by nuclear reaction analysis using the ${ }^{2} \mathrm{H}\left({ }^{3} \mathrm{He}, p\right){ }^{4} \mathrm{He}$ nuclear reaction at $700 \mathrm{keV}$, for the $4 \mathrm{~nm}$ UVZO-HfSiO/Si and $2 \mathrm{~nm}$ UVZO-HfSiON/Si structures after the indicated annealing sequences, performed from left to right. ${ }^{2} \mathrm{H}_{2}$-loading and $450{ }^{\circ} \mathrm{C}$ preannealing were for $30 \mathrm{~min}$, whereas $1000^{\circ} \mathrm{C}$ rapid thermal preannealing were for $10 \mathrm{~s}$. The precision in the ${ }^{2} \mathrm{H}$ areal densities is $10 \%$.

\begin{tabular}{cccccc}
\hline \hline \multicolumn{3}{c}{ Annealing sequences } & & & \multicolumn{2}{c}{$\begin{array}{c}{ }^{2} \mathrm{H} \text { areal density } \\
\left(10^{14} \mathrm{~cm}^{-2}\right)\end{array}$} \\
\cline { 5 - 6 } \cline { 5 - 6 } $\mathrm{N}_{2}$ & $\mathrm{O}_{2}$ & ${ }^{2} \mathrm{H}_{2}$ & & $\begin{array}{c}\mathrm{HfSiO} / \mathrm{Si} \\
4 \mathrm{~nm}\end{array}$ & $\begin{array}{c}\mathrm{HfSiON} / \mathrm{Si} \\
2 \mathrm{~nm}\end{array}$ \\
${ }^{\circ} \mathrm{C}$ & ${ }^{\circ} \mathrm{C}$ & ${ }^{\circ} \mathrm{C}$ & & & \\
\hline$\ldots$ & $\ldots$ & 500 & & 8.6 & 3.5 \\
450 & $\cdots$ & 500 & & 4.9 & 4.1 \\
$\ldots$ & 450 & 500 & & 5.7 & 1.4 \\
450 & 450 & 500 & & 2.2 & 0.8 \\
1000 & $\cdots$ & 500 & & 0.4 & 0.3 \\
1000 & 1000 & 500 & & 0.4 & 0.25 \\
\hline \hline
\end{tabular}

(not shown), decreases significantly during annealing in $\mathrm{O}_{2}$ at $1000^{\circ} \mathrm{C}$.

The ${ }^{2} \mathrm{H}$ loading in as-prepared react- and UVOZsamples cannot be directly compared for different reasons, including the following: (i) The very large difference in thickness of the two groups of samples, (ii) the differences in relative oxygen and nitrogen content and defect structures in the two groups, resulting from the two different preparation routes, and (iii) the thickness differences within the UVOZ$\mathrm{HfSiO}$ and $\mathrm{HfSiON}$ group of samples, which may require a normalization to equal thicknesses. When normalized to equal thicknesses, the incorporated amounts of ${ }^{2} \mathrm{H}$ in nonpreanneled UVOZ-HfSiO and UVOZ-HfSiONare rather similar.

In summary, hydrogen and deuterium were seen to incorporate in nitrided and non-nitrided hafnium silicate films on $\mathrm{Si}$ to amounts that exceed by one order of magnitude those found in silicon oxide and oxynitride films. This is a consequence of the more rigid metal silicate (nitrided or not) structures of the present work in which, compared to silicon oxide(oxynitride), a growth defect is less likely to be healed during annealing as this would require significant rearrangement of a number of neighboring bonds. ${ }^{2 \xi-25}$ Preannealing in different atmospheres at moderate temperatures $\left(400-500^{\circ} \mathrm{C}\right)$ was able to strongly reduce the areal densities of incorporated hydrogen(deuterium), although their profiles remained unaltered. Different incorporated amounts for different preannealing atmospheres revealed the different nature of the H-trapping defects in nitrided and non-nitrided silicates, namely mainly structural defects in hafnium silicate and mainly stoichiometric ones in nitrided hafnium silicates. Three additional facts are also certainly influencing the incorporation of $\mathrm{H}$ in react- and UVOZ-samples, namely the different $\mathrm{O}-\mathrm{H}$ and $\mathrm{N}-\mathrm{H}$ bond strength, oxygen incorporation (stoichiometry completion), and $\mathrm{N}$ loss during annealing, owing mainly to $\mathrm{N}-\mathrm{O}$ exchange. ${ }^{21}$ Annealing at tem- peratures as high as $1000^{\circ} \mathrm{C}$ implied an even larger reduction in defect density and $\mathrm{N}$ losses, and therefore in hydrogen(deuterium) incorporation. The bond rearrangements underlying this effect also explain the observed film densification during annealing at high temperatures.

The authors would like to acknowledge financial support from the Brazilian agencies CAPES, CNPq and FAPERGS. R.M.W. acknowledges the support of the National Science Foundation from the Americas program of the Office of International Science and Engineering (\#0314153) and the U.S. Army Soldiers Systems Center (DAAD16-00-C-9273).

${ }^{1}$ G. D. Wilk, R. M. Wallace, and J. M. Anthony, J. Appl. Phys. 89, 5243 (2001).

${ }^{2}$ High-k Gate Dielectrics, edited by M. Houssa (IOP, London, 2004).

${ }^{3}$ R. M. C. de Almeida and I. J. R. Baumvol, Surf. Sci. Rep. 49, 1 (2003).

${ }^{4}$ M. R. Visokay, J. J. Chambers, A. L. P. Rotondaro, A. Shanware, and L. Colombo, Appl. Phys. Lett. 80, 3183 (2002).

${ }^{5}$ A. Shanware, M. R. Visokay, J. J. Chambers, A. L. P. Rotondaro, H. Bu, M. J. Bevan, R. Khamankar, P. E. Nicollian, J. McPherson, and L. Colombo, IEEE International Reliability Physics Symposium Proceedings, 2003, p. 208.

${ }^{6}$ M. Quevedo-Lopez, M. El-Bouanani, M. J. Kim, B. E. Gnade, R. M. Wallace, M. R. Visokay, A. LiFatou, J. J. Chambers, and L. Colombo, Appl. Phys. Lett. 82, 4669 (2003).

${ }^{7}$ C. Hinkle and G. Lucovsky, Appl. Surf. Sci. 216, 124 (2003).

${ }^{8}$ H. J. Cho, K. C.S., K. Onishi, S. Gopalan, R. Nieh, C. R., S. Krishnan, and J. C. Lee, IEEE Electron Device Lett. 23, 249 (2002).

${ }^{9}$ M. Quevedo-Lopez, M. El-Bouanani, M. J. Kim, B. E. Gnade, R. M. Wallace, M. R. Visokay, A. LiFaton, J. J. Chambers, and L. Colombo, Appl. Phys. Lett. 81, 1074 (2002).

${ }^{10}$ H. Sim and H. Hwang, Appl. Phys. Lett. 81, 4038 (2002).

${ }^{11}$ A. Stesmans and V. V. Afanas'ev, Appl. Phys. Lett. 82, 4074 (2003).

${ }^{12}$ J. W. Lyding, K. Hess, and I. Kiziyalli, Appl. Phys. Lett. 68, 2526 (1996).

${ }^{13}$ I. J. R. Baumvol, E. P. Gusev, F. C. Stedile, F. L. Freire, Jr., M. L. Green, and D. Brasen, Appl. Phys. Lett. 72, 450 (1998).

${ }^{14} \mathrm{~J}$. Krauser, A. Weidinger, and D. Bräuning, in The Physics and Chemistry of $\mathrm{SiO}_{2}$ and of the $\mathrm{Si}_{\mathrm{S}} \mathrm{SiO}_{2}$ Interface-3, edited by H. Z. Massoud, I. J. R. Baumvol, I. Hirose, and E. Poindexter (The Electrochemical Society, Pennington, 1996), p. 184.

${ }^{15}$ C. Krug, E. P. Gusev, E. A. Cartier, and T. H. Zabel, J. Appl. Phys. 95, 887 (2004).

${ }^{16}$ E. H. Poindexter and P. J. Caplan, J. Vac. Sci. Technol. A 6, 390 (1988).

${ }^{17}$ I. J. R. Baumvol, Surf. Sci. Rep. 36, 1 (1999).

${ }^{18}$ R. J. Carter, E. Cartier, A. Kerber, L. Pantisano, T. Schram, and S. De Gendt, Appl. Phys. Lett. 83, 533 (2003).

${ }^{19}$ J. Morais, L. Miotti, G. V. Soares, R. P. Pezzi, S. R. Teixeira, K. P. Bastos, I. J. R. Baumvol, A. L. P. Rotondaro, M. Visokay, and L. Colombo, Appl. Phys. Lett. 81, 2995 (2002).

${ }^{20}$ P. Punchaipetch, G. Pant, M. Quevedo-Lopez, H. Zhang, M. El-Bouanani, M. J. Kim, R. M. Wallace, and B. E. Gnade, Thin Solid Films 425, 68 (2003).

${ }^{21}$ K. P. Bastos, J. Morais, L. Miotti, R. P. Pezzi, G. V. Soares, I. J. R. Baumvol, R. I. Hedge, H. H. Tseng, and P. J. Tobin, Appl. Phys. Lett. 81, 1669 (2002).

${ }^{22}$ R. Choi, K. Onishi, S. C. Kang, H.-J. Cho, Y. H. Kim, S. Krishnan, M. S. Akbar, and J. C. Lee, IEEE Electron Device Lett. 24, 144 (2003).

${ }^{23}$ S. M. Myers, J. Appl. Phys. 61, 5428 (1987).

${ }^{24}$ S. Sugano and Y. Tanabe, Thansition Metal Ions in Crystals (Academic, New York, 1970).

${ }^{25}$ I. B. Bersuker, Electronic Structure and Properties of Transition Metal Compounds (Wiley-Interscience, New York, 1996). 